\title{
Fish-heads and breadcrumbs to feed the five thousand
}

\section{John Rivers}

Nutrition and Food Science: Present Knowledge and Utilization. Edited by Walter J. Santos et al. Three-volume set. Vol. 1, Food and Nutrition Programs and Policies, pp.850, ISBN 0-306-40342-0. Vol. 2, Nutrition Education, Food Science and Technology, pp.900, ISBN 0-306-40343-9. Vol. 3, Nutritional Biochemistry and Pathology, pp.758, ISBN 0-306-40344-7. (Plenum: 1980.) Vol. 1 $\$ 75$, £47.25; Vol. 2 \$79.50, £50.09; Vol. 3 $\$ 69.50, £ 43.79$. Three-volume set $\$ 195$, $£ 122.88$.

Nutrition and Food Science is a weighty work: three volumes, 2,500 pages, 750,000 words. That is about as long as the Bible or the complete works of Shakespeare. It seems reasonable to ask if these three books measure up to such standards.

The answer, sadly, is no. These volumes will rarely be read, and even more rarely enjoyed. They cannot even be treated as a coherent work: they are a patchwork of 250 essays linked by the fact that their authors attended the Eleventh International Congress of Nutrition in Brazil, 1978.

The editors have given each volume a subtitle and subdivided each volume, presumably to impose some order on them, but this attempt fails. For example the title for Vol. 2, Nutrition Education, Food Science, and Technology, is in itself a portmanteau. Fittingly so, since the volume is further subdivided into four parts - Animal and Vegetable Resources for Human Feeding, Food Science and Technology, Research in Food Nutrition (sic) and Nutrition Education - and since national nutrition surveys are put in Vol. 2 even though Vol. 1 seems more appropriate.

In this electronic age the international congress is becoming an anachronism. In small fields, especially fast-moving ones, it is still a feasible and important way of communicating. But all too often congresses are only "holidays for the boys". The cliche that the best science is discussed in the bar is actually a two-edged one.

Some time ago the Economist magazine, in an article on scientific research, noted that, of the 32 participants at an international physics conference in 1927, a third were, or were to be Nobel Laureates. An equivalent meeting in 1980 had 800 participants, no Nobel prizewinners and only routine investigations were reported. The Economist should have dissected nutrition. The triennial International Nutrition Congresses have doubled in size about every ten years. The science they represent grows only one-quarter as fast, so necessarily the congresses have become less and less important as a legitimate part of scientific communication, and more and more a social event.

At the Eleventh Congress, 5,000 participants gathered together in Brazil and seem to have achieved nothing: were all those journeys really necessary? Like a somewhat more famous gathering of 5,000 they subsisted on a very meagre diet. But if a miraculous transformation of the loaves and fishes of their intellects occurred, then it must be the baskets of leftover rubbish that have been published for posterity.

For that is what this work is about. It is a three-volume commemoration of an event. There are some good, original papers, such as Jul's study on dairy farming in Calcutta, but they are few, and will probably be lost in the mound of fish-heads and breadcrumbs. A mound of papers in which nothing much is said, in which most tables and graphs seem to be referred back to previous publications, in which representatives of commercial organizations are simply reporting the use of their products, and a collection which overall could have done with refereeing and extensive subediting.

Nutrition and Food Science is a reverberating cry for something to be done to stem the flow of paper that is dignified by the appellation "scientific literature" This is neither science nor literature.

John Rivers is a Lecturer in the Department of Human Nutrition at the London School of Hygiene and Tropical Medicine, University of London.

\section{Depth in stability for the cognoscenti}

\section{P.H. Roberts}

Hydrodynamic Stability. By P.G. Drazin and W.H. Reid. Pp.525. ISBN 0-521-22798-4. (Cambridge University Press: 1981.) £35, $\$ 77$.

"NoT every solution of the equations of motion, even if it is exact, can actually occur in nature. The flows that occur in nature must not only obey the equations of fluid dynamics, but also be stable". The significance of this apt quotation from Landau and Lifshitz with which the authors of Hydrodynamic Stability open their book is evident from the scarcity in nature of simple orderly ("laminar") motions and the abundance of irregular ("turbulent") flows. The transition from the former to the latter starts with the instability of the laminar flow, a process that can be studied in controlled laboratory conditions and, with comparative ease, by theoreticians.

The achievements of stability theorists are now so extensive that the authors had to make hard decisions in limiting their text to even 525 pages. They have opted for depth, rather than breadth, of treatment, and paid particular attention to classic situations such as Bénard convection, circular (Couette) flow and plane parallel flow.

A consideration in the authors' choice of topics was probably the existence of Chandrasekhar's classic work, Hydrodynamic and Hydromagnetic Stability (Clarendon Press, 1961). Wonderful though Chandrasekhar's treatise is, it is sometimes felt today that it contains a number of lacunae: it overstresses variational methods; it ignores a useful technique (asymptotic analysis); it omits one of the oldest and possibly the mathematically most interesting of all linear stability problems, that raised by plane Poiseuille flow; and it says little about non-linear stability. None of these points would have been fair criticism in 1961 when the book was published, but today many specialists will welcome Drazin and Reid's account, if for no better reason than because it successfully redresses the balance.

The authors are of course well known, particularly for their work on parallel flows, and it is here that readers will discover the most penetrating discussions, and the deepest and most elegant mathematics. Indeed, some may wonder whether the authors' enthusiasm has carried them too far, and whether all of the sophisticated theoretical weapons displayed are essential to their own armouries. This space might have been better used in expounding non-linear theory still further, or in providing deeper discussions of baroclinic instabilities, another subject that has exploded since Chandrasekhar wrote his book. Most readers will find the discussion of pinch instabilities frustratingly brief.

These are minor reproaches only. The work is undeniably of high scholarship, consummate accuracy and penetrating insight. Teachers of graduate courses will find the problems at the end of each chapter imaginative, but difficult: solutions can be obtained by application to either author. All specialists in stability theory will be happy that two such authorities have found the time, and spared so few pains, to produce a work of such excellence.

P.H. Roberts is Professor of Applied Mathematics at the University of Newcastle upon Tyne. 